\title{
Aprendizagens do "tornar-se", das experiências formadoras e da visibilidade: aproximações entre autobiografias e educação
}

\section{Learning from "becoming", training experiences and visibility: approximations between autobiographies and education}

\author{
André Augusto Diniz Lira* \\ Maria da Conceição Passeggi**
}

\begin{abstract}
RESUMO
Ainda que a educação seja um empreendimento coletivo, histórico e circunstanciado, a dinâmica do sujeito da aprendizagem é perpassada por sua existencialidade e por sua singularidade. Nosso objetivo, neste artigo, é analisar aprendizagens biográficas significativas na construção do tornar-se escritor, nas autobiografias literárias de Manuel Bandeira (18861968), Lêdo Ivo (1924-2012) e Ferreira Gullar (1930-2016). O critério de variabilidade foi decisivo para a escolha desses autores, posto que suas obras são marcadas por diferentes gerações e escolas literárias. Nosso olhar tem como base abordagens (auto)biográficas em educação, que interrogam a experiência da formação na temporalidade do sujeito, partindo de um enfoque epistemológico no qual a subjetividade é crucial. Para tanto, consideramos, inicialmente, a discussão entre autobiografia e educação; posteriormente, avaliamos como as aprendizagens biográficas se apresentam nas trajetórias dos autores estudados. Os resultados das análises consideram três dinâmicas de aprendizagem em suas vidas: a) tornar-se si mesmo; b) as experiências formadoras constitutivas da escrita autobiográfica;
\end{abstract}

* Universidade Federal de Campina Grande. Campina Grande, Paraíba, Brasil. E-mail: andreaugustoufcg@gmail.com - https://orcid.org/0000-0001-9398-507X

** Universidade Cidade de São Paulo. São Paulo, São Paulo, Brasil. E-mail: mariapasseggi@ gmail.com - https://orcid.org/0000-0002-4214-7700 
c) a visibilidade ética e estética do mundo. Concluímos discutindo a importância dessas aprendizagens na proposição de uma educação para a singularidade que recupere esses elementos da aprendizagem biográfica de forma dinâmica e agregadora.

Palavras-chave: Educação. Aprendizagem. Autobiografias literárias. Autoria.

\begin{abstract}
Although education is a collective, historical, and circumstantial enterprise, the dynamics of the subject of learning is permeated by his/her existentiality and his/her uniqueness. Our objective, in this article, is to analyze significant biographical learning in the construction of becoming a writer, in the literary autobiographies written by Manuel Bandeira (1886-1968), Lêdo Ivo (1924-2012), and Ferreira Gullar (1930-2016). The variability criterion was crucial in the choice of these authors, since their works are marked by different generations and literary schools. Our view is based on (auto) biographical approaches to education, which interrogate the experience of training in the subject temporality, starting from an epistemological approach in which subjectivity is crucial. For this purpose, we initially consider the discussion between autobiography and education and, later, we evaluate how biographical learning is presented in the trajectories of the writers studied. The results of the analysis consider three learning dynamics in their lives: a) becoming oneself; b) training experiences constitutive of autobiographical writing; c) ethical and aesthetic visibility of the world. We conclude by discussing the importance of this learnings in proposing an education for the singularity that recovers these elements of biographical learning in a dynamic and aggregating way.
\end{abstract}

Keywords: Education. Learning. Literary autobiographies. Authorship.

\title{
Introdução
}

As biografias e as autobiografias, enquanto gêneros literários, destacam-se, por um lado, por sua fecundidade no mercado editorial e, por outro, como objeto de estudo dos mais perscrutados em Filosofia, História e Literatura. É a partir de meados do século XX, período denominado por Dosse (2015) de idade hermenêtica, que essas escritas sobre o outro (biografia) e sobre si mesmo (autobiografia) ganham relevância redobrada, acompanhando a guinada interpretativa nas ciências humanas e sociais. 
A rigor, desde o início do século XX, Wilhelm Dilthey (1833-1911) tomará a autobiografia como a "forma mais elevada e mais instrutiva" para a compreensão epistemológica do mundo histórico nas ciências sociais, pelo viés da vivência, da expressão e da compreensão, pois nela o sujeito concretizaria reflexivamente a "conexão na história de sua vida" (DILTHEY, 2010, p. 178-179). A discussão sobre a singularidade e a multiplicidade, típicas dessa virada interpretativa, já teria marcado também os saberes psicológicos, desde a sua constituição e de diversos modos. Freud, por exemplo, escreveu em 1925 uma autobiografia intelectual no intuito de contribuir para a história da Psicanálise, e apresentou um breve pós-escrito em 1935 (FREUD, 1976).

É apenas por volta do último quartel do século XX, que perspectivas mais subjetivas e enfoques mais narrativos passam a ser incorporados em educação (NÓVOA, 1995; FONTANA, 2000). As abordagens (auto)biográficas em educação, desde os anos 1980, vêm contribuído para uma melhor compreensão das escritas de si na constituição da subjetividade e processos de formação humana e profissional. A orientação de cunho reflexivo e prático na formação docente, por exemplo, suscitou no Brasil um campo de pesquisa frutífero sobre a docência e identidade docente. As pesquisas com biografias e autobiografias literárias não tiveram, no entanto, o mesmo crescimento, tendo por base fundamentos narrativos, psicológicos e educacionais, com propósitos formativos explícitos e de aprendizagem. O diálogo mais corrente ficou mais restrito aos estudos históricos e literários ${ }^{1}$.

O objetivo deste artigo é analisar aprendizagens biográficas mais significativas na construção do tornar-se escritor nas autobiografias literárias de Manuel Bandeira (1886-1968), Lêdo Ivo² (1924-2012) e Ferreira Gullar (1930-2016). O critério de variabilidade foi crucial na escolha desses autores, posto que suas obras são entrecortadas por diferentes gerações e escolas literárias. Apesar de as aprendizagens serem múltiplas e subjetivadas de modo particular por cada ser humano, trata-se de saber se podemos encontrar processos semelhantes em histórias de vida tão diferenciadas.

1 Para uma compreensão das abordagens (auto) biográficas em História e Literatura, cf. Vasconcelos, Cordeiro, Vicentini (2014) e de forma mais ampla cf. Passeggi, M. (2020). Sobre esse (auto) "enclausurado" por parênteses também cf. Passeggi, M. (2020).

2 Para análise de Lêdo Ivo, recorremos principalmente ao livro Confissões de um Poeta (IVO, 2004), mas também lançamos mão dos livros O Ajudante de Mentiroso (IVO, 2009) e O Aluno Relapso. Afastem-se das Hélices (IVO, 2013). Uma exposição mais completa do autobiográfico em Lêdo Ivo pode ser encontrada em Lira e Passeggi $(2018,2020)$. 
Nosso olhar tem como base as abordagens (auto)biográficas ${ }^{3}$, que interrogam a experiência da formação na temporalidade do sujeito, partindo de um enfoque epistemológico no qual a subjetividade é crucial, pondo em relevo a reflexividade narrativa e o sujeito autobiográfico (PASSEGGI, M., 2016), em oposição às matrizes científicas [e cientificistas] hegemônicas (DELORY-MOMBERGER, 2008). Segundo Delory-Momberger (2012, p. 524), nessa abordagem, não se trata de uma singularidade solipsista, mas de "uma singularidade atravessada, informada pelo social, no sentido em que o social lhe dá seu quadro e seus materiais".

No tocante à aprendizagem biográfica, Alheit e Daussien (2006, p. 179) consideram que não se trata de procedimentos de apropriação progressiva de saberes, ela se refere mais propriamente "ao processo altamente organizado da perlaboração, da ligação e da (trans)formação dos primeiros processos de aprendizagem em uma figura biográfica de experiências, ou seja, de algum modo uma 'segunda ordem' de processos de aprendizagem". Diferentemente das abordagens clássicas de aprendizagem, as autobiografias literárias devem ser entendidas como um processo amplo que possibilita uma relação complexa entre a autobiografia e heterobiografia, implicando a participação ativa do autor e do leitor. (DELORY-MOMBERGER, 2008, 2019). Segundo a autora, no ato de recepção da narrativa relaciono o que ouço ou leio com os meus próprios constructos biográficos, compreendendo-os "nas relações de ressonância e de inteligibilidade com minha própria experiência biográfica" (DELORY-MOMBERGER, 2008, p. 59-60).

Este artigo decorre de estudos e publicações anteriores do primeiro autor sobre o escritor Lêdo Ivo (LIRA; PASSEGGI, L., 2018; LIRA, 2019; LIRA; PASSEGGI, L., 2020) ${ }^{4}$, de reflexões conduzidas pela segunda autora no campo da pesquisa (auto)biográfica (PASSEGGI, M., 2010, 2011, 2016, $2020)^{5}$ e de projetos financiados pelo Conselho Nacional de Desenvolvimento Científico e Tecnológico (CNPq). Antes de adentrar na discussão dos resultados, necessitamos situar a autobiografia como um dos recursos educativos, uma vez que essa relação não é direta.

3 Incluímos nas abordagens (auto)biográficas, a Biographieforschung, de tradição alemã; a Biographical research, desenvolvida principalmente na Inglaterra; a Investigación biográficonarrativa, na Espanha e países de América Latina de língua espanhola; a Recherche biographique, na França; Narrative inquiry, no Canadá e Pesquisa (auto)biográfica, no Brasil.

4 Este trabalho é um dos desdobramentos de um estágio pós-doutoral do primeiro autor, realizado no Programa de Pós-Graduação em Estudos da Linguagem da Universidade Federal do Rio Grande do Norte. Faz parte também de um projeto de pesquisa mais amplo, desenvolvido no Programa de Pós-graduação em Educação da Universidade Federal de Campina Grande, intitulado "Representações discursivas identitárias em Lêdo Ivo: a construção de um modelo interpretativo".

5 Publicações no site do GRIFARS-UFRN-CNPq. Disponível em: http://grifars.ce.ufrn.br/. $\mathrm{O}$ artigo está vinculado ao projeto de pesquisa em andamento: Passeggi, M. Narrativas, educação, saúde: epistemologia e métodos da pesquisa (auto)biográfica com crianças (MCTI/CNPq Chamada $n^{\circ}$ 06/2019, processo n. 307063/2019-4). 


\section{Autobiografias e Educação}

Os dicionários técnicos são recursos fundamentais para compreendermos como um conceito em uma determina área do conhecimento revela as forças instituídas no campo científico. No caso em tela, partimos das definições encontradas em três dicionários especializados: o Dicionário de gêneros textuais de Sérgio Roberto Costa (2009); o Dicionário de Termos Literários de Massaud Moisés (2013) e o Dicionário de Estudos Narrativos de Carlos Reis (2018).

Costa (2009, p. 38) define a autobiografia como uma "narração (v.) sobre a vida de um indivíduo, escrita por ele próprio, sob a forma documental, ou seja, é uma prosa, que uma pessoa real faz de sua própria existência, acentuando a vida individual, em particular, sobre a história de sua personalidade", admitindo que ela pode ser ou não literária. Observamos, nessa definição, uma aproximação com a primeira perspectiva traçada por Lejeune (2014), por sua vez baseada em dicionários de língua. Para Costa, o que diferencia a autobiografia do romance seria a característica "do autor contar fatos e não ficções" (COSTA, 2009, p. 38-39). Considera ainda que há na autobiografia uma coincidência entre o autor, o narrador e a personagem. Essas últimas características são questionadas na literatura mais específica da área, inclusive no desenvolvimento da obra de Philippe Lejeune (2014).

Em seu Dicionário de Termos Literários, Massaud Moisés (2013, p. 47) destaca inicialmente os elementos etimológicos e históricos do termo. Sublinha que "a atividade literária por ele designada remonte aos primeiros séculos do cristianismo, mais precisamente desde Agostinho e suas Confissões, escritas no ano de 400". Todavia, ainda que faça menção a Agostinho, Moisés desconsidera, na mesma página, sua importância, pois seria necessária uma "consciência histórica", enquanto as Confissões narrariam "os transes de sua dramática conversão, cedendo primazia a Deus". Observamos aqui uma leitura cientificista da autobiografia e da verdade, ao elencar as lacunas suscitadas: pela falta de confiança [fato de o autor distorcer seu passado por esquecimento, por amplificar ou minorar fatos], pelo narcisismo do autor e até pelo próprio estilo utilizado, adequando-se aos "padrões da moda". O descrédito para com a autobiografia é ressaltado mais uma vez na compreensão de sua utilidade, ao restringir seu valor à pena de um autor famoso, pois revelaria "um testemunho que ao escritor foi dado em presenciar sua escalada vital" (MOISÉS, 2013, p. 48).

A compreensão de Moisés (2013) e de Costa (2009) ao considerarem a compreensão dicotômica entre verdade e ficção, já não mais se sustenta, mesmo nas áreas para as quais esses dicionários estão direcionados, assim como 
pela complexidade da discussão sobre a escrita biográfica e autobiográfica. Por outro lado, o Dicionário de Estudos Narrativos de Carlos Reis (2018), que tem por base, entre outros autores, Philippe Lejeune, Georges Gusdorf, Paul Ricœur, amplia a discussão do conceito de autobiografia, considerando seus aspectos formais, ontológicos e temáticos. Reis (2018.) discute também aspectos identitários, estruturais (sobretudo relativo ao tempo) e de expressão da subjetividade, sublinhando a valorização da "experiência de quem conta, em harmonia com exemplaridade dos acontecimentos relatados, entendidos como merecedores de atenção e até de registro histórico" (REIS, 2008, p. 36). Observamos que, nesse sentido, esse dicionário diversifica a discussão acadêmica sobre a autobiografia e aponta para uma perspectiva educacional na medida em que ressalta a exemplaridade.

Os dicionários de Costa (2009) e de Moisés (2013) não levaram em consideração, ou não aprofundaram, a rica discussão histórico-conceitual e epistemológica, que se erigiu, direta ou indiretamente, desde a obra de Wilhelm Dilthey (1833-1911), passando por Mikhail Bakhtin (1895-1975), Paul Ricoeur (1913-2005) e Jerome Bruner (1915-2016), assim como em obras mais específicas (BRUNER, 2014; DILTHEY, 2010; DOSSE, 2015; GUSDORF, 1991; LEJEUNE, 2014; LYLE, 2018). Algumas considerações gerais são necessárias, tendo em vista a construção da perspectiva que adotamos, ancorada na pesquisa (auto)biográfica, que põe em relevo a questão educativa. Já salientamos anteriormente que há questionamentos sobre o sentido educativo da autobiografia, tecidos no seio do pós-estruturalismo e no que se denominou de desconstrução, baseados sobretudo na obra de Nietsche, conforme Duque-Estrada (2009). Discutiremos, a seguir, autores que se aproximam das abordagens narrativas numa perspectiva mais educacional.

A obra de Wilhelm Dilthey traz uma discussão epistemológica do mundo histórico nas ciências sociais pelo viés da vivência, da expressão e da compreensão, pondo em destaque a autobiografia como sua "forma mais elevada e mais instrutiva", considerando que nela o sujeito concretizaria reflexivamente uma "conexão na história de sua vida" (DILTHEY, 2010, p. 178-179). Na autobiografia se realizam e se encontram o valor, a finalidade e o significado da vida. "Nós interpretamos a vida como a realização de uma verdade suprema, à qual se subordinam todas as finalidades particulares, como a concretização de um bem supremo" (DILTHEY, 2010, p. 180).

Convém sublinhar o lugar da instrução e do exemplo no encontro entre pessoas, sendo "a compreensão um reencontro do eu no tu" (DILTHEY, 2010, p. 168). E na inspiração dessa epistemologia que não trata apenas de um mero individualismo metodológico ou idiossincrático, Carino reflete sobre o entrecruzamento entre a história e as imagens dos homens postas em movimento: 
[...] tempos heroicos exigem a biografia de heróis, tempos românticos exigem que as vidas retratadas exibam romantismo; épocas históricas regidas pelo condão da fé exigem que as biografias sejam hagiografias, retratando a pureza e a retidão dos santos (CARINO, 1999, p. 157).

Em um outro direcionamento, mas ainda destacando o valor da autobiografia em sua dimensão educativa, Gusdorf (1991) enfatizará questões de cunho existencial da singularidade das trajetórias humanas, do testemunho que ela evoca por ser uma fonte de sabedoria sobre a vida. Segundo o autor, a autobiografia trata-se de uma "obra de arte", "obra de edificação", fonte de autoconfrontação e de fascinação narcísica. Uma outra característica importante, segundo Gusdorf(1991), é o estabelecimento de uma relação temporal dinâmica, onde o que importa não é a cronologia, mas o tempo vivenciado, assim, "no podría ser pura y simplemente, un proceso verbal de la existencia, un libro de cuentas, un diario de campaña: tal día, a tal hora, fue a tal lugar... Tal tipo de cuentas, aunque minuciosamente exacto, no sería más que una caricatura de la vida real" (GUSDORF, 1991, p. 12).

De todos os autores mencionados acima, Lejeune (2014) é o autor mais conhecido e referenciado no que diz respeito às autobiografias. A análise de Lejeune é mais empírica do texto e dos mecanismos que nele operam. $\mathrm{O}$ autor partiu das definições de dicionários de autobiografia, mas também apresentou um quadro inovador, à época, ao entrecruzar o nome do personagem ao pacto possível estabelecido com o leitor na obra, em uma tabela do tipo $3 X 3,[\neq$ nome do autor, $=0,=$ nome do autor] $\times$ [romanesco, $=0$, autobiográfico]. Lejeune viria a reconsiderar sua obra inúmeras vezes, incorporando novos textos em prosa, que lhes eram desconhecidos como contraexemplos, inclusive textos de caráter híbrido. Lejeune discutiu amplamente sobre outros textos de natureza autobiográfica, sobre a ficcionalidade e a internet, entre outros. A obra desse autor e sua sinceridade ao revisá-la constantemente, entre outras lições, demonstra que as autobiografias, nos últimos anos, têm se complexificado, inclusive a relação linear entre autor, personagem e o nome de quem escreveu a autobiografia.

Outras abordagens discutem mais as dimensões de cunho psicológico e educacional. É o caso dos estudos de Bruner (1997), que ocupam um lugar importante nesse âmbito. $\mathrm{O}$ autor discute a autobiografia no quadro da sua psicologia popular, que leva em consideração o ponto de vista do sujeito, suas relações de compromisso, seu estilo de vida, seus interesses e sobretudo o pensamento narrativo, como elemento fundante do ser humano, que desde pequeno seria um verdadeiro contador de histórias para os outros e para si mesmo. O si mesmo seria uma construção narrativa de si e dos outros que 
também o constituem. As narrativas de si espelham também a imagem que o sujeito constrói sobre suas capacidades, suas ações e as repercussões, de seu lugar no mundo.

Partindo de uma leitura de cunho psicológico e educacional, Lyle (2018) realizou uma pesquisa sobre a contribuição das narrativas autobiográficas para o desenvolvimento da identidade e da integridade. Essa pesquisadora elaborou cinco premissas baseadas no conhecimento sobre autobiografias em educação, defendendo que: a) ensinar é um trabalho autobiográfico; b) bons professores vinculam identidade à integridade; c) construímos nossa identidade por meio das narrativas; d) promovemos a integridade ao problematizar os paradigmas dicotômicos. Por fim, e) estabelece uma linha de continuidade com a discussão sobre os selves possiveis ou selves alternativos, na perspectiva de Markus e Nurius (1986), que foi também apropriado por Bruner na obra citada anteriormente.

No conjunto, esses autores ressaltam o valor da autobiografia e do seu enlace em educação de um ponto de vista amplo. A educação do sujeito pela leitura de romances que retraçam a história de uma vida era uma das finalidades dos conhecidos romances de formação, bildungsroman de tradição alemã. Assim, autobiografias podem ser compreendidas como textos que permitem várias possibilidades de formação, pela relação que se estabelece entre os processos de autobiografização e heterobiografização, que já aludimos anteriormente.

\title{
Aprendizagens do tornar-se si mesmo
}

\begin{abstract}
Decerto desde criança me preparei silenciosamente para ser eu mesmo, para me tornar mim mesmo. Era uma operação subterrânea. Eu queria exprimir-me, comunicar-me. Eu queria ser. [...] Aprendi que essa operação, destinada a converter as experiências vividas em arte, reclamava um determinado uso da linguagem, exigia uma competência que só poderia ser obtida se a minha vida fosse uma interminável aprendizagem (IVO, 2009, p. 15).
\end{abstract}

A caminhada da aprendizagem se efetiva de modo ideal pela conjunção entre cognição e emoção, entre a vontade e a constituição de um projeto pessoal, que se desdobra em um fazer ou vários fazeres. Em todas as autobiografias analisadas, as relações tecidas com a aprendizagem se evidenciam em muitos 
aspectos. Bruner (2008) afirma que compreendemos muito da mente humana com os estudos de suas deficiências e patologias. Para o autor (2008, p. 30), conhecer "o suave voo da mente humana, operando de sua melhor forma" é também um desafio. O nosso interesse de lançar mão de escritos autobiográficos se direciona para a compreensão dessa dinâmica "operando em sua melhor forma".

Em primeiro lugar, os autores analisados buscaram o aprimoramento de suas técnicas de escrita por meio de uma aprendizagem contínua. Manuel Bandeira se destaca por uma leitura negativa de suas potencialidades pela via do perfeccionismo que o movimenta: "meus versos não passavam de um exercício poético, sem sombra de poesia, e onde inegavelmente, nada havia de bonito" (BANDEIRA, 2012, p. 54), e mais adiante: "Que ingenuidade a minha, e eu já tinha vinte e oito anos feitos" (BANDEIRA, 2012, p. 71). Contudo, essas limitações o incentivam como lições: "Meditei na lição e até hoje em toda a poesia que escrevo me lembro dela e procuro só pronunciar as palavras essenciais" (BANDEIRA, 2012, p. 75).

Em sua autobiografia, Manuel Bandeira descreve a sua trajetória como uma carreira desviada da Arquitetura, que se apresenta como uma sombra constante em sua vida poética, como uma vida que deveria ter sido e não foi possível realizar-se. Ao mesmo tempo, a tuberculose, que o coloca na iminência da morte diariamente, foi também um canal para o desenvolvimento da carreira de escritor. O tornar-se poeta aqui se entrecruza, do início ao fim, com o emblema da busca por Pasárgada que é para Bandeira (2012, p. 24) "toda a vida que podia ter sido e não foi". O tornar-se se institui assim como um tema inquietante para Bandeira, o da poesia e da vida vivida e não vivida. Sua identidade de poeta é, portanto, a realização de uma outra vida.

Lêdo Ivo, por outro lado, é um poeta esbanjador e se situa numa compreensão positiva de si mesmo, como um eterno e ávido aprendiz, como podemos ler na epígrafe acima. Esse projeto-trajeto se afigura com uma identidade prospectiva, na perspectiva em que ele busca uma atestação. $\mathrm{Na}$ leitura que Taylor (2013) fez de Ricœur, a identidade prospectiva se desenha no horizonte de expectativas, nas possibilidades futuras e no senso da incompletude. O domínio da arte escrita caminha para Lêdo Ivo junto com a aprendizagem da técnica, da leitura dos grandes escritores e da busca da perfeição, ainda que inencontrável. Sua trajetória poética, visada quando criança, apontava para uma realidade: "exigia uma competência que só poderia ser obtida se a minha vida fosse uma interminável aprendizagem" (IVO, 2009, p. 15). A linguagem e a sua obra são, portanto, constitutivas dele próprio: “Transformei-me aos poucos, numa criação de minha própria criação" (IVO, 2004, p. 101).

Ferreira Gullar não demonstra a mesma proximidade com o sentimento de vocação poética, desde a infância, ela seria mais propriamente uma relação 
estabelecida na juventude. Sua caminhada foi feita de percalços, de crises pessoais e de recuos para com a linguagem, a ponto de evitar escrever até em português em determinado momento de sua vida. "Tomara-me de tal horror pelo uso normal do idioma que, como tinha que responder a carta de um amigo de São Luís, escrevi-lhe em francês" (GULLAR, 2015, p. 35). No seu trajeto pessoal, o reconhecimento paulatino de que a linguagem em que se expressava "era velha", o levou a novas formas de escrever e fazer poemas, considerando inclusive a materialidade da expressão poética. Após várias lutas tecidas consigo mesmo e com a linguagem, a poesia que segundo o autor era a sua vida, readquiriu novamente significado. As palavras adquiriram formas e movimentos no espaço, emergindo daí sua relação com o movimento neoconcretista.

Nas autobiografias analisadas, podemos perceber diferentes nuanças na forma como essas aprendizagens são apresentadas pelos autores. São aprendizagens de si. Aprendizagens biográficas. Dilthey (2010), como já discorremos, considera que as autobiografias apontam para a realização de um projeto supremo que dá sentido a todos subprojetos ou afazeres articulados a esse propósito maior. Seria necessário encontrar nelas esse sentido. Em síntese, para Bandeira, tornar-se poeta é viver à sombra de uma vida não vivida, o que o faz ir em busca de Pasárgada. Para Lêdo Ivo, "tornar-se escritor" é traçar um trajeto a ser alcançado, um glorioso casamento com a linguagem. Para Gullar, é uma descoberta em meio a crises consigo mesmo e com a linguagem. Mais propriamente, uma descoberta da linguagem para além da linearidade.

A aprendizagem do tornar-se, vista pelo olhar dos próprios autores, implica, portanto, uma série de elementos, tais como a autenticidade, as expansões e as delimitações do eu. Várias abordagens psicológicas ressaltam essa busca de si mesmo como uma conquista do eu, como uma procura da autenticidade. Na leitura de Rogers (1991), o desenvolvimento pessoal deve passar necessariamente pelo "tornar-se pessoa". Alguns princípios são basilares em sua teoria: a congruência, a aceitação incondicional do outro, a experiência integral de relações afetivas, a afeição em relação a si mesmo. Em geral, tanto terapeutas quanto professores são compreendidos como facilitadores da aprendizagem, admitindo-se, com Rogers (1991), que a caminhada do desenvolvimento pessoal é um processo individual e único, que deve ser trilhado pelo próprio sujeito.

Na obra de Winnicott $(1990 ; 1996)$, as definições do "verdadeiro self" e do "falso self" são eixos fundamentais para o desenvolvimento do ser. Segundo o autor, o self verdadeiro caminha junto com o gesto espontâneo, com a criatividade, com a integração, desde a mais terna idade. Sua compreensão de desenvolvimento humano incorpora as relações com a mãe e com os vários ambientes que podem ser acolhedores e propiciadores do desenvolvimento. 
A família e a escola são instituições que têm um papel crucial no handling (manejo) e no holding (sustentação). Esses conceitos não se reduzem à compreensão do desenvolvimento da criança, pois, o que é brincadeira na infância, em uma relação metafórica, será o trabalho no adulto. Para Winnicott (1990; 1996), o “falso self”, em contraposição, é adaptativo, repetindo padrões institucionalizados que produzem assujeitamento; sendo, portanto, patológicos ou submissos à realidade ordenada e imposta. Vale salientar, no entanto, que para Winnicott, o self adaptativo é também necessário, por se constituir uma defesa do eu. Em alguns casos clínicos, o psicanalista observou que essa era a única forma de sobreviver.

Finalmente, esse tornar-se si mesmo se relaciona com processos amplos de aprendizagem consigo mesmo, com os outros e com o mundo. Para Luft (2004), esse tornar-se/processo pode ser visto como uma transgressão, pois se reveste de uma reinvenção, de uma reflexão autobiográfica, de tal modo que se ancora na sabedoria de "Questionar o que nos é imposto, sem rebeldias insensatas, mas sem demasiada sensatez". E nessa configuração, continua a autora: "Suportar sem se submeter, aceitar sem se humilhar, entregar-se sem renunciar a si mesmo e à possível dignidade" (LUFT, 2004, p. 23).

\title{
Aprendizagens das experiências formadoras
}

\begin{abstract}
Mas uma coisa é certa - ele me fazia sentir nos grandes escritores do passado esse elemento indefinível que é o gênio da língua, a que sempre se mostrou tão particularmente sensível. A sua lição foi, e continuou sendo vida afora, muito preciosa para a minha experiência poética (BANDEIRA, 2012, p. 33).
\end{abstract}

A discussão sobre a relação entre experiência e educação é histórica. Comenius, Rousseau, Dewey e Piaget, para citar apenas os mais lembrados, cada um ao seu modo, discorreram sobre o lugar da experiência no desenvolvimento pessoal. As reflexões sobre a experiência ocupam um lugar privilegiado nas abordagens biográficas. De acordo com Nóvoa (2010), a formação do adulto sempre esteve impregnada pelo modelo escolar, sendo compreendida como uma preparação no presente para agir no futuro. Para o autor, uma nova epistemologia da formação desenvolve-se a partir dos anos 1980, tendo como um de seus pilares a abordagem biográfica, a investigação-ação e a reflexividade. 
Larrosa $(2004,2016)$ tem aproximado a discussão entre experiência, narrativa e identidade, destacando o papel da literatura na construção dos sujeitos. Para o autor, as experiências têm sido, na contemporaneidade, negligenciadas pelo excesso de informação, pelo excesso de opinião, pela falta de tempo e pelo excesso de trabalho. Concordamos com o autor, em parte. A busca idílica por um tempo outro, por vivências de experiências ideais, já não é a realidade da maioria das pessoas em formação, quer seja por esses excessos (de opinião, de trabalho, de informações), quer seja pela falta (de tempo, de trabalho, de informações), todavia, acreditamos que esses excessos e ausências também fazem parte de aprendizagens biográficas.

Conforme Josso (2004, p. 48), o conceito de "experiência formadora" é crucial, pois remete a "uma articulação conscientemente elaborada entre atividade, sensibilidade, afetividade e ideação", com grandes repercussões para nos tornar quem somos. As aprendizagens para essa autora estariam vinculadas aos conhecimentos existenciais: instrumentais e pragmáticos; compreensivos e explicativos. Conhecimentos que, diferentemente de abordagens cognitivistas, relacionam-se com o eu: como me conheço enquanto ser psicossomático, ser capaz de interagir e ser capaz de representar.

Admitimos, portanto, que as 'autobiografias literárias' permitem identificar exemplos das experiências complexas e integradoras de aprendizagens que remetem ao si mesmo. Em um trabalho anterior, Lira e Passeggi propõem que a experiência educativa na obra de Lêdo Ivo caminha para um olhar holístico e integrador das experiências, combinando razão e sensibilidade, leitura do mundo e leitura da palavra, tendo ainda uma alternância mutualmente constitutiva (LIRA; PASSEGGI, L., 2018). Essa experiência integra, numa sinfonia, conjuntos articulados de elementos: a) da natureza (mar, ondas, sol, mangue, praia, da própria maresia e seus efeitos); b) dos animais e insetos (gavião, urubu, caranguejo, caranguejeira, formiga); c) de objetos do mundo (o farol, o navio, a porta).

Em autobiografias literárias de diferentes gerações e de diferentes campos do saber, é possível depreender a importância do outro na constituição de si mesmo, para alguns(mas) autores(as), uma professora, para outros a esposa ou marido, um amigo ou amiga, pais ou personagens da vida literária ou artística com quem se relacionaram. Esses outros constitutivos de si podem ser ainda figuras conhecidas por suas histórias, escritos, atitudes. Bandeira (2012, p. 27), recorda-se, por exemplo, do pai: “Assim, na companhia paterna ia-me eu embebendo dessa ideia que a poesia está em tudo - tanto nos amores como nos chinelos, tanto nas lógicas como nas disparadas". Ao analisar a rua do Curvelo, constitutiva de sua experiência poética, é com certa desesperança que entrelaça as lembranças da rua e de seu pai, convocando o leitor a pensar na própria história e na história da família. 
A morte do meu pai e a minha residência no Morro do Curvelo de 1920 a 1930 acabaram de amadurecer o poeta que sou. Quando meu pai era vivo, a morte ou o que pudesse acontecer não me preocupava, porque eu sabia que pondo a minha mão na sua, nada haveria que eu não tivesse coragem de enfrentar. E era só que eu teria que enfrentar a pobreza e a morte (BANDEIRA, 2012, p. 82).

Por outro lado, as experiências dos outros e com os objetos do conhecimento podem se revelar também como lições de vida no sentido positivo e motivacional. É talvez por isso que as biografias e as autobiografias de pessoas que se destacam por sua genialidade em diferentes domínios da atividade humana são tão requisitadas. Ao estudar profissionais de alto rendimento, Csikszentmihalyi (1992) discute sobre o self autotélico, pelo qual o indivíduo entra em processo de fluxo como uma experiência agregadora que conjuga metas, mergulho na atividade, concentração no que está acontecendo e satisfação com a experiência. Essa experiência se faz pela ludicidade, como exemplificada na biografia de Ferreira Gullar que, em vários momentos, reflete sobre o movimento de sua construção poética e de si mesmo:

[...] entreguei-me a uma espécie de aventura imprevisível, em que o poema foi tomando forma e significação, para minha surpresa e alegria. [...] Ora escrevia versos que se estruturavam em combinação com o branco da página, jogo de palavras e silêncio; ora abandonava esse rumo e escrevia poemas em prosa, desafiando a lógica do discurso; depois voltava ao verso, mas noutro estágio de experimentação da aventura. Deve-se entender, porém, que essa é a visão que tenho hoje do que acorreu então; naquele momento, apenas vivia a experiência sem me preocupar em entendê-la (GULLAR, 2015, p. 25).

Gullar e Ledo Ivo destacaram a importância que tiveram suas professoras primárias ao reconhecer seus potenciais. Gullar vê no espelho da professora, que o iluminou, o gosto pela linguagem, e como se deu conta de que poderia escrever até algo melhor. Ledo Ivo, por ser aluno destacado, foi levado a conversar com Graciliano Ramos, que ocupava então o cargo de diretor de ensino de sua escola, em Maceió. Esse encontro do jovem Ivo com um grande expoente da literatura brasileira jamais seria esquecido em sua vida de autor: "O sertanejo agreste pousou a mão em minha cabeça. Até hoje este surpreendente gesto de carinho me segue e persegue, como se fora uma antecipação, e anúncio de um destino" (IVO, 2009, p. 276). 
Contudo, as experiências, como já afirmamos, podem se manifestar de várias maneiras. Para Gullar (2015, p. 23), a leitura de Hoffman, em um livro tomado de mofo, encontrado em um sebo em São Luís, serviu para refletir sobre ele mesmo: "Mas curiosa foi a conclusão e que, aparentemente, não tem relação com ele: 'A literatura só terá sentido se mudar alguma coisa, nem que seja a minha própria vida". Essa relação da leitura de Hoffman na autorreflexão do poeta nos faz lembrar dos vínculos entre autobiografia e heterobiografía, embora nem sempre a história não suscite uma relação direta e imediata com quem a lê, ela pode levar a refletir sobre si mesmo de forma indireta, como sugere Delory-Momberger (2008).

\section{Aprendizagens da visibilidade}

Um bule. Uma maça. Um vaso de flores. Os olhos de um cão. O exercício espiritual da visão é indispensável aos poetas que só aprendem a ver desde que saibam fixar-se nas coisas mais banais e cotidianas. [...] Saber ver é um dever poético. E a vida exige muito olho para ser vista (IVO, 2004, p. 28).

A fotografia é uma escrita tão forte porque pode ser lida em todo o mundo sem tradução (SALGADO; FRANCQ, 2014, p. 58).

Como vimos anteriormente, as experiências com os outros são fundantes na tarefa de construir as próprias experiências, e é nesse sentido que Manuel Bandeira destaca a importância de seu pai na aprendizagem da visibilidade. Essa aprendizagem do olhar, que é transposta para um "fazer ver", não é necessariamente uma imagética transformada em palavras. Pode ser um sentimento, um cheiro, uma sensação a ser transmitida. Gullar (2015) laborou, por dias, para transmitir, no formato de um poema, a sensação que teve ao se deparar com o cheiro exalado de uma tangerina, que seu filho descascava na sala de sua casa. Para tanto, suas inquirições sobre como escrever o poema o levou ao estudo das tangerinas, somente depois desse estudo conseguiu escrever.

Os autores aqui estudados consideram que a visibilidade é uma forma privilegiada de "observação comunicada", que pode colocar em relevo, tanto uma "estética" do mundo invisibilizado, quanto uma "ética" para o mundo. A dimensão estética não se acompanha necessariamente de uma ética política, mas pode fazer vislumbrar uma ética para a vida, para o bem viver como uma ponte para reflexão existencial. Bandeira (2012), ao refletir sobre uma viagem 
corriqueira que se tornou singular, conjuga estética, reflexividade, senso de finitude e completude em um único momento:

A ida para lá, noite fechada ainda, foi a viagem mais bonita que fiz na minha vida. Vênus luzia sobre nós tão grande, tão intensa, tão bela, que chegava a parecer escandalosa e dava vontade de morrer (daquela hora é que iria sair o título do meu livro seguinte: Estrela da Manhã) (BANDEIRA, 2012, p. 116).

Essa ética e estética marca também a vida de Sebastião Salgado, quando afirma no livro em coautoria com Francq (SALGADO, FRANCQ, 2014), que contou histórias fotográficas por meio de sua obra. Essas histórias estavam marcadas por sua autobiografia, seu ponto de vista e o que ele considerava como missão: revelar as mazelas e as injustiças do mundo e contra o mundo. $\mathrm{O}$ que pode passar despercebido para um olhar desavisado, Salgado explicita as marcas da reflexividade narrativa, de sua sensibilidade e da própria dimensão autobiográfica, por trás das fotografias que fez ao longo de sua vida.

Todas as minhas fotos correspondem a momentos intensamente vividos por mim. Todas elas existem porque a vida, a minha vida, me levou até elas. Porque dentro de mim havia uma raiva que me levou àquele lugar. [...] Minha fotografia não é nada objetiva. Como todos os fotógrafos, fotografo em função de mim mesmo, daquilo que me passa pela cabeça, daquilo que estou vivendo e pensando (SALGADO; FRANCQ, 2014, p. 47).

Depois de anos labutando com essas histórias fotográficas, sua autobiografia (SALGADO; FRANCQ, 2014), ilumina sua obra imagética. Nesse sentido, Lêdo Ivo, ao refletir sobre a criação artística, ponderou: "Aos poetas, como aos demais criadores, cabe a tarefa ou a missão de proceder à visibilidade do universo. A poesia é uma arte de ver - de ver e saber ver o que, mesmo sob os nossos olhos, só pode ser distinguido pelo uso e iluminação da linguagem" (IVO, 2013 , p. 129). Essas aprendizagens da visibilidade levam a uma pedagogia do olhar. Um ensino mediado por imagens e palavras, que expressam de variadas maneiras artifícios da subjetividade e da singularidade humanas bem como sua indignação: "Minhas fotos foram tiradas, porque pensei que o mundo inteiro deveria saber. Fiz essas fotografias porque eu tinha uma obrigação moral, ética de fazê-las (SALGADO; FRANCQ, 2014, p. 94). 


\section{Considerações provisórias}

Ao longo deste artigo, consideramos o valor das autobiografias literárias para compreendermos a aprendizagem biográfica em seus "melhores voos", no dizer de Bruner (2008). Esse tipo de aprendizagem tem a vantagem de evidenciar um conjunto de aspectos comumente tratados de forma isolada e dicotomizada do desenvolvimento humano. Seria possível pinçar, no estreito caminho da singularidade humana, as marcas biográficas da aprendizagem e com elas refletir sobre suas potencialidades para a educação?

As aprendizagens do tornar-se poeta, escritor, ou simplesmente do tornar-se humano, se fazem mediante experiências formadoras e do olhar estético que conduzem a desafios e tensões no âmbito escolar. Uma educação do tornar-se deveria se encaminhar para processos mobilizadores de aprendizagens biográficas, processos de reconhecimento das singularidades, processos de encontros na relação eu-tu. Uma educação generalista dificilmente contribuirá para que os indivíduos se reconheçam no outro e reconheçam a si mesmos como sujeitos que elaboram seus pensamentos, suas emoções e seus trajetos de formas distintas. Uma educação de experiências formadoras contribuiria para aprendizagens que elaboram saberes numa relação contínua com a própria vida. Nesse sentido, uma série de aspectos devem figurar na compreensão de que apesar de sua importância, não são apenas os conteúdos disciplinares que se tornam indispensáveis ao humano para se tornar quem é.

A relação com saber é perpassada pela relação com os objetos do conhecimento, mediada pelo outro e com o outro. Uma educação da visibilidade, que aguça o olhar, não se pode apreender sem um trabalho contínuo de observação do mundo, do outro e de si mesmo no tempo longo das aprendizagens. Essa aprendizagem do olhar é uma tarefa crucial para uma educação da singularidade, porque descentra o si mesmo de suas idiossincrasias. A educação do olhar é uma abordagem arquitetada que permite ver e entrever a vida e as aprendizagens da experiência vivida.

Então, qual seria o lugar das autobiografias literárias em uma educação para o tornar-se? Elas podem ser um importante contributo a ser explorado para se compreender o lugar das experiências, da reflexividade narrativa, das aprendizagens biográficas, da relação eu-tu, da visibilidade pela educação do olhar. Evidentemente, não se trata de uma panaceia nem de uma única trilha. É apenas um dos percursos possíveis, que nos aventuramos a percorrer aqui. 


\section{REFERÊNCIAS}

ALHEIT, Peter; DAUSIEN, Bettina. Processo de formação e aprendizagens ao longo da Vida. Educação e Pesquisa, São Paulo, v. 32, n. 1, p. 177-197, jan./abr. 2006. Disponível em: https://www.scielo.br/scielo.php?script=sci_arttext\&pid =S1517-97022006000100011. Acesso em: 10 abr. 2020 .

BANDEIRA, Manuel. Itinerário de Pasárgada. São Paulo: Global, 2012.

BRUNER, Jerome S. Atos de Significação. Porto Alegre: Artmed, 1997.

BRUNER, Jerome S. Fabricando Histórias. São Paulo: Letra e Voz, 2014.

BRUNER, Jerome S. Sobre o Conhecimento: ensaios da mão direita. São Paulo: Phorte, 2008.

CARINO, Jonaedson. A biografia e sua finalidade educativa. Educação \& Sociedade, Campinas, ano XX, n. 67, p. 153-178, ago. 1999. Disponível em: https://www.scielo. br/pdf/es/v20n67/v20n67a05.pdf. Acesso em: 03 mar. 2020.

CSIKSZENTMIHALYI, Mihaly. A Psicologia da Felicidade. São Paulo: Saraiva, 1992.

COSTA, Sérgio Roberto. Dicionário de Gêneros Textuais. 2 ed. versão ampliada. Belo Horizonte: Autêntica, 2009.

DELORY-MOMBERGER, Christine. Abordagens metodológicas na pesquisa biográfica. Revista Brasileira de Educação, Rio de Janeiro, v. 17, n. 51, p. 523-536, set./dez. 2012.

DELORY-MOMBERGER, Christine. Biografia e Educação: figuras do indivíduo projeto. Natal: EDUFRN; São Paulo: Paulinas, 2008.

DELORY-MOMBERGER, Christine. Vocabulaire des histoires de vie et de la Recherche biographique. Toulouse: Érès, 2019.

DILTHEY, Wilhelm. A construção do mundo histórico nas ciências humanas. São Paulo: Editora UNESP, 2010.

DOSSE, François. O desafio biográfico: escrever uma vida. São Paulo: EDUSP, 2015.

DUQUE-ESTRADA, Elizabeth Muylaert. Devires autobiográficos: a atualidade da escrita de si. Rio de Janeiro: NAU: Editora PUC-Rio, 2009.

FONTANA, Roseli Cação. Como nos tornamos professoras? Belo Horizonte: Autêntica, 2000.

FREUD, Sigmund. Um estudo autobiográfico, Inibições, Sintomas e Ansiedade, Análise Leiga e outros trabalhos (1925-1926). Rio de Janeiro: Imago, 1976. v. 20 (Edição standard brasileira das obras psicológicas completas de Sigmund Freud).

GULLAR, Ferreira. Autobiografia poética e outros textos. Belo Horizonte: Autêntica, 2015.

GUSDORF, Georges. Condiciones y límites de la autobiografia. Anthropos: Boletín de información y documentacion, Barcelona, n. 29, p. 9-18, 1991. 
IVO, Lêdo Confissões de um poeta. Rio de Janeiro: Topbooks, 2004.

IVO, Lêdo. O Ajudante de Mentiroso. Rio de Janeiro: Educan, 2009.

IVO, Lêdo. O Aluno Relapso. Afastem-se das Hélices. Rio de Janeiro: Apicuri, 2013.

JOSSO, Marie-Christine. Experiências de Vida e Formação. São Paulo: Cortez, 2004.

LARROSA, Jorge. Notas sobre a narrativa e identidade: a modo de presentación. In: ABRAHÃO, Maria Helena Barreto. A Aventura (Auto)biográfica: teoria e empiria. Porto Alegre: EDIPUCRS, 2004. p. 11-22.

LARROSA, Jorge. Tremores: escritos sobre experiência. Belo Horizonte: Autêntica, 2016.

LEJEUNE, Philippe. O pacto autobiográfico: de Rousseau à internet. 2 ed. Belo Horizonte: Editora da UFMG, 2014.

LIRA, André Augusto Diniz. Por uma aprendizagem das experiências na infância: literatura e (auto)formação em "O Ajudante de Mentiroso" de Lêdo Ivo. Revista @mbienteeducação, São Paulo, v. 12, p. 181-198, maio/ago. 2019. Disponível em: https://doi.org/10.26843/ae19828632v12n22019p181a198. Acesso em: 07 abr. 2020.

LIRA, André Augusto Diniz; PASSEGGI, Luis. Lêdo Ivo: o jogo identitário do ser/ fazer-se poeta. In: PASSEGGI, Maria da Conceição; LANI-BAYLE, Martine; FURLANETTO, Ecleide Cunico; ROCHA, Simone Maria da (org.). Pesquisa (auto) biográfica em educação: infâncias e adolescências em espaços escolares e não escolares. Natal: EDUFRN, 2018, p. 397-414.

LIRA, André Augusto Diniz; PASSEGGI, Luis. De aluno relapso a pensador transgressor: representações discursivas identitárias em Lêdo Ivo. Campina Grande: EDUFCG, 2020.

LUFT, Lya. Pensar é transgredir. Rio de Janeiro: Record, 2004.

LYLE, Ellyne. Possible selves: restor(y)ring wholeness through autobigraphical writing. Learnig Lands Scapes, Quebec, Canadá, v. 11, n. 2, p. 257-269, 2018. Disponível em: https:/www.learninglandscapes.ca/index.php/learnland/article/view/961. Acesso em: 5 mar. 2020.

MARKUS, Hazel; NURIUS, Paula. Possible Selves. American Psychologist, v. 41, n. 9, p. 954-969, sep. 1986. Disponível em: https://www.researchgate.net/publi cation/232565363_Possible_Selves. Acesso em: 18 fev. 2020.

MOISÉS, Massaud. Dicionário de Literatura. 12 ed. rev. amp. São Paulo: Cultriz, 2013.

NÓVOA, António. A Formação tem que passar por aqui: as histórias de vida no Projeto Prosalus. In: NÓVOA, António; FINGER; Mathias (org.). O método (auto)biográfico e a formação. Natal: EDUFRN; São Paulo: Paulus, 2010. p. 155-187.

NÓVOA, António. Os professores e suas histórias de vida. In: NÓVOA, António (org.). Vidas de Professores. Porto: Porto Editora, 1995. p. 11-30. 
PASSEGGI, Maria da Conceição. Abordagens narrativas na pesquisa educacional brasileira - Enfoques narrativos en la investigación educativa brasileña. Revista Paradigma, Maracay Edo Aragua, Venezuela, Vol. XLI, p. 57-79, junio 2020. (Edición Cuadragésimo Aniversario: 1980-2020). Disponível em: http://revistaparadigma.online/ ojs/index.php/paradigma/article/view/929. Acesso em: 10 jun. 2020.

PASSEGGI, Maria da Conceição. Narrativas da experiência na pesquisa-formação: do sujeito epistêmico ao sujeito biográfico. Revista Roteiro. Joaçaba, v. 41, p. 67-86, 2016. Disponível em: https://portalperiodicos.unoesc.edu.br/roteiro/article/view/9267. Acesso em: 12 dez. 2019.

PASSEGGI, Maria da Conceição. A experiência em formação. Educação. Porto Alegre, v. 34, p. 147-156, 2011. Disponível em: https://revistaseletronicas.pucrs.br/ojs/index. php/faced/article/view/8697. Acesso em: 12 dez. 2019.

PASSEGGI, Maria Conceição. Narrar é humano! Autobiografar é um processo civilizatório. In: PASSEGGI, Maria Conceição; SILVA, Vivian Batista da (org.). Invenções de vidas, compreensão de itinerários e alternativas de formação. São Paulo: Cultura Acadêmica, 2010, p. 103-130.

REIS, Carlos. Dicionário de Estudos Narrativos. Coimbra: Almedina, 2018.

ROGERS, Carl. Tornar-se pessoa. São Paulo: Martins Fontes, 1991.

SALGADO, Sebastião; FRANCQ, Isabelle. Da minha Terra à Terra. São Paulo: Paralela, 2014.

TAYLOR, George. Identidade Prospectiva. In: NASCIMENTO, Fernando; SALLES, Walter (org.). Paul Ricoeur: ética, identidade e reconhecimento. Rio de Janeiro: Editora PUC; São Paulo: Loyola, 2013. p. 127-147.

VASCONCELOS, Maria Celi Chaves; CORDEIRO, Verbena Maria Rocha; VICENTINI, Paula Perin (org.). (Auto)biografia. Literatura e história. Curitiba: CRV, 2014.

WINNICOTT, Donald Woods. O ambiente e os processos de maturação: estudos sobre a teoria do desenvolvimento emocional. Porto Alegre: Artes Médicas, 1990.

WINNICOTT, Donald Woods. Tudo começa em casa. 2 ed. São Paulo: Martins Fontes, 1996.

Texto recebido em 04/08/2020.

Texto aprovado em 15/09/2020. 